\title{
Quality of life of young male catheterized patients
}

\author{
Pramanik S. ${ }^{1}$, Paul U.K. ${ }^{2}$, Pal D.K. ${ }^{3}$ \\ ${ }^{1}$ Dr. Sandip Pramanik, Post Doctoral Trainee, Urology Department, IPGMER, Kolkata, West Bengal, ${ }^{2}$ Dr. Uttam Kumar \\ Paul, Professor, Department of Medicine, MGM Medical College, Kishanganj, Bihar, ${ }^{3}$ Dr. Dilip Kumar Pal, Professor \& \\ Head, Urology Department, IPGMER, Kolkata, West Bengal, India.
}

Corresponding Author: Dr. Dilip Kumar Pal, Professor \& Head, Urology Department, IPGMER, Kolkata, West Bengal, India. E-mail: urologyipgmer@gmail.com,drdkpal@yahoo.co.in

\begin{abstract}
Introduction: It is pointless to point out that, Per-urethral or Supra-pubic Catheter compromises the Quality of life (QoL) of young male patients. Our study is about the comparison of QoL status along with depression of catheterized state with same after removal of catheter of patients. Objectives: In our study we wanted to quantify the quality of life $(\mathrm{QoL})$ and distress experienced by patient following catheterisation and also to assess the improvement of QoL after catheter removal following surgical intervention. Methods: We used two tools named World Health Organization Quality of Life scale (WHOQOL BREF) and Beck Depression Inventory (BDI) for this purpose. Result: We found statistically significant improvements in all domains of QoL as measured by WHOQOL BREF and improvement in depression status as well, measured by Beck Depression Inventory (BDI). Conclusion: As we have documented poor QoL and depression status in catheterised state and improvement of the same after catheter removal we recommend counselling of such patients regarding QoL and Psychiatry consultation for management of depression.
\end{abstract}

Keywords: BDI, Catheterization, WHOQOL BREF, QoL

\section{Introduction}

Young male patients may present with urinary retention due to various reasons like urethral stricture disease, bladder neck obstruction, bladder or urethral stone disease etc. They may require catheterisation if they develop acute urinary retention. Many of those patients require some form of surgical intervention for removal of catheter. All these interventions not only affect the physical, social, sexual and emotional health of patient but also the immediate family member of patient specially his spouse.

The deterioration of Quality of Life (QoL) in the patients with one urinary catheter (either per-urethral or supra-pubic) has been documented in number of studies which we shall be referring to in the following paragraphs. Ikuerowo SO et al after their study in Nigeria on 62 patients with urinary catheter for an Acute Urinary Retention (AUR) and waiting for definitive surgical interventions concluded that it is a painful experience to have an indwelling urinary catheter for a considerable period and it is associated with several side effects also.

Manuscript received: $10^{\text {th }}$ October 2018

Reviewed: $20^{\text {th }}$ October 2018

Author Corrected: $26^{\text {th }}$ October 2018

Accepted for Publication: $30^{\text {th }}$ October 2018
They did also mention that this catheterized state leads to negative effect on the QoL of patients on significant amount and financial burden to government and patients. They suggested few measures such as to reduce the waiting time for surgery in the intent of reducing the period of indwelling catheterization [1].

Fumincelli L et al after their study assessing the QoL of patient on intermittent self catheterization concluded that improvement in the urinary symptoms, selfconfidence, access to work activities, independence as well as social relationships and social insertion can determine the QoL of neurogenic bladder patients using intermittent urinary catheterization [2].

Wilde $\mathrm{M}$ et $\mathrm{al}^{3}$ after their study on 202 adult community-living long-term indwelling urinary catheter users has documented that excess morbidity and health care utilization and costs are attributed to long term urinary catheter. In our study we wanted to quantify the quality of life (QoL) distress experienced by patient following catheterisation and also to assess the improvement of QoL after catheter removal following surgical intervention. 


\section{Materials and Methods}

Place of Study: The study was done at the Urology department of IPGMER Kolkata, West Bengal, India. Prior approval was taken from the Institutional Ethical Committee.

Type of Study: It is a prospective study.

Period of Study: From 16th March 2017 to 15th March 2018

Sampling Methods: Every young male catheterized patient (21-40 years) admitted at Urology ward, IPGMER, who has given consent for the study has been included in the study.

Sample Collection: QoL Questionnaire is given to patients following two weeks of per urethral catheter (PUC) / suprapubic catheter (SPC) insertion in patients. The patients undergoing surgical intervention for catheter removal are again administered QOL questionnaire following 2 weeks of PUC/SPC removal of the patients. We compared the data of both states by standard statistical analysis. Sample size was 43 . The patients are assessed for quality of life by using following instruments:

- Following 2 weeks after catheterization of patient (before any intervention)

○ WHOQOL-BREF [4]

○ BDI (Beck's Depression Inventory) [5]

- Following 2 weeks after the patient becomes catheter free (following intervention)

○ WHOQOL-BREF [4]

○ BDI (Beck's Depression Inventory[5]

WHOQOL BREF [4] is an instrument devised by World Health Organisation to assess the quality of life in human subjects. This questionnaire is about how the subject feels about his quality of life, health, or other areas of his life. He has to answer all the questions. If he is unsure about which response to give to a question, he is instructed to choose the one which appears most appropriate. There are 26 items and four domains named Domain 1: Physical Health, Domain 2: Psychological, Domain 3: Social relationships, Domain 4: Environment. Scores are summed up according to domain and are analysed.

Beck's Depression Inventory is a similar kind of scale measuring depression. There are 21 questions and the subject has to score each of them. The total score will tell us the state of depression in the subject. The scoring system is shown in table 1 .

Table-1: (Beck's Depression Inventory Score)

\begin{tabular}{|c|c|}
\hline Total Score & Levels of Depression \\
\hline $1-10$ & These ups and downs are normal \\
\hline $11-16$ & Mild mood disturbance \\
\hline $17-20$ & Borderline clinical depression \\
\hline $21-30$ & Moderate depression \\
\hline $31-40$ & Severe depression \\
\hline Over 40 & Extreme depression \\
\hline
\end{tabular}

Inclusion Criteria: In this prospective study young male catheterized patients (21-40 years) admitted at Urology ward were included in the study.

Exclusion Criteria: Those denying consent and patients presenting with urinary retention for medical problems were excluded.

Statistical Methods: Statistical Analysis was performed with help of EPI INFO (TM) 7.2.2.2. 


\section{Results}

Statistical Analysis was performed with help of EPI INFO (TM) 7.2.2.2; EPI INFO is a trademark of the Centres for Disease Control and Prevention (CDC). Descriptive statistical analysis was performed to calculate the means with corresponding standard deviations (S.D.). Test of proportion was used to find the Standard Normal Deviate (Z) to compare the difference proportions. T-test was used to compare the means.p $<0.05$ was taken to be statistically significant.

Analysis of WHOQOL BREF score at different domains of the patients:

For Domain-1 (Physical Health):

Table- 2: Comparison of WHOQOL BREF score for Domain- I of the patients.

\begin{tabular}{|c|c|c|c|c|c|c|}
\hline \multirow{2}{*}{$\begin{array}{l}\text { Descriptive } \\
\text { Statistics }\end{array}$} & \multicolumn{2}{|l|}{ Raw Score } & \multicolumn{2}{|c|}{ Transformed Score (4-20) } & \multicolumn{2}{|c|}{ Transformed Score (0-100) } \\
\hline & $\begin{array}{c}\text { Catheterized } \\
\text { state }\end{array}$ & $\begin{array}{c}\text { After Catheter } \\
\text { removal }\end{array}$ & $\begin{array}{c}\text { Catheterized } \\
\text { state }\end{array}$ & $\begin{array}{c}\text { After Catheter } \\
\text { removal }\end{array}$ & $\begin{array}{c}\text { Catheterized } \\
\text { state }\end{array}$ & $\begin{array}{c}\text { After Catheter } \\
\text { removal }\end{array}$ \\
\hline Mean+SD & $15.63 \pm 3.27$ & $18.95 \pm 1.36$ & $8.98 \pm 1.88$ & $10.77 \pm 0.68$ & $31.28 \pm 11.73$ & $42.60 \pm 4.11$ \\
\hline Median & 15.00 & 19.00 & 9.00 & 11.00 & 31.00 & 44.00 \\
\hline Range & $11-21$ & $17-21$ & $6-12$ & $10-12$ & $13-50$ & $38-50$ \\
\hline t-test & \multicolumn{2}{|c|}{6.15} & \multicolumn{2}{|c|}{5.85} & \multicolumn{2}{|c|}{5.97} \\
\hline $\mathrm{p}$-value & \multicolumn{2}{|c|}{$<0.0001 *$} & \multicolumn{2}{|c|}{$<0.0001 *$} & \multicolumn{2}{|c|}{$<0.0001^{*}$} \\
\hline
\end{tabular}

T-test showed that the means of all the scores after the removal of catheter was significantly higher than that of at catheterised state $(\mathrm{p}<0.0001)$. Thus the mean of all the scores after the removal of catheter significantly increased (Shown in table 2).

For Domain-2 (Psychological health):

Table-3: Comparison of WHOQOL BREF score for Domain-II of the patients.

\begin{tabular}{|c|c|c|c|c|c|c|}
\hline \multirow{2}{*}{$\begin{array}{c}\text { Descriptive } \\
\text { Statistics }\end{array}$} & \multicolumn{2}{|c|}{ Raw Score } & \multicolumn{2}{c|}{ Transformed Score (4-20) } & \multicolumn{2}{c|}{ Transformed Score (0-100) } \\
\cline { 2 - 7 } & $\begin{array}{c}\text { Catheterized } \\
\text { state }\end{array}$ & $\begin{array}{c}\text { After Catheter } \\
\text { removal }\end{array}$ & $\begin{array}{c}\text { Catheterized } \\
\text { state }\end{array}$ & $\begin{array}{c}\text { After Catheter } \\
\text { removal }\end{array}$ & $\begin{array}{c}\text { Catheterized } \\
\text { state }\end{array}$ & $\begin{array}{c}\text { After Catheter } \\
\text { removal }\end{array}$ \\
\hline Mean+SD & $12.58 \pm 3.74$ & $15.86 \pm 2.03$ & $8.81 \pm 3.38$ & $10.49 \pm 1.47$ & $27.95 \pm 16.16$ & $40.65 \pm 9.43$ \\
\hline Median & 12.00 & 16.00 & 8.00 & 11.00 & 25.00 & 44.00 \\
\hline Range & $8-21$ & $14-21$ & $5-17$ & $9-14$ & $6-63$ & $31-63$ \\
\hline t-test & \multicolumn{2}{|c|}{5.04} & 2.94 & & 4.44 \\
\hline p-value & \multicolumn{2}{|c|}{$<0.0001 *$} & $<0.0001 *$ & $<0.0001 *$ \\
\hline
\end{tabular}

T-test showed that the means of all the scores after the removal of catheter was significantly higher than that of at catheterised state $(\mathrm{p}<0.001)$. Thus the mean of all the scores after the removal of catheter significantly increased (Shown in table 3).

For Domain-3 (Social relationships):

Table-4: Comparison of WHOQOL BREF score for Domain-III of the patients.

\begin{tabular}{|c|c|c|c|c|c|c|}
\hline \multirow{2}{*}{$\begin{array}{c}\text { Descriptive } \\
\text { Statistics }\end{array}$} & \multicolumn{2}{|c|}{ Raw Score } & \multicolumn{2}{c|}{ Transformed Score (4-20) } & \multicolumn{2}{c|}{ Transformed Score (0-100) } \\
\cline { 2 - 7 } & $\begin{array}{c}\text { Catheterized } \\
\text { state }\end{array}$ & $\begin{array}{c}\text { After Catheter } \\
\text { removal }\end{array}$ & $\begin{array}{c}\text { Catheterized } \\
\text { state }\end{array}$ & $\begin{array}{c}\text { After Catheter } \\
\text { removal }\end{array}$ & $\begin{array}{c}\text { Catheterized } \\
\text { state }\end{array}$ & $\begin{array}{c}\text { After Catheter } \\
\text { removal }\end{array}$ \\
\hline Mean+SD & $7.40 \pm 1.98$ & $8.93 \pm 1.30$ & $9.86 \pm 2.45$ & $11.95 \pm 1.80$ & $36.63 \pm 15.15$ & $49.74 \pm 11.31$ \\
\hline Median & 7.00 & 9.00 & 9.00 & 12.00 & 31.00 & 50.00 \\
\hline Range & $5-10$ & $7-11$ & $7-13$ & $9-15$ & $19-56$ & $31-69$ \\
\hline t-test & \multicolumn{2}{|c|}{4.25} & 4.52 & 4.54 \\
\hline p-value & \multicolumn{2}{|c|}{$<0.001 *$} & \multicolumn{2}{c|}{$<0.0001 *$} & $<0.001 *$ \\
\hline
\end{tabular}




\section{Original Research Article}

T-test showed that the means of all the scores after the removal of catheter was significantly higher than that of at catheterised state $(\mathrm{p}<0.0001)$. Thus the mean of all the scores after the removal of catheter significantly increased (Shown in table 4).

For Domain-4 (Environment):

Table-5: Comparison of WHOQOL BREF score for Domain-IV of the patients.

\begin{tabular}{|c|c|c|c|c|c|c|}
\hline \multirow{2}{*}{$\begin{array}{c}\text { Descriptive } \\
\text { Statistics }\end{array}$} & \multicolumn{2}{|c|}{ Raw Score } & \multicolumn{2}{c|}{ Transformed Score (4-20) } & \multicolumn{2}{c|}{ Transformed Score (0-100) } \\
\cline { 2 - 7 } & $\begin{array}{c}\text { Catheterized } \\
\text { state }\end{array}$ & $\begin{array}{c}\text { After Catheter } \\
\text { removal }\end{array}$ & $\begin{array}{c}\text { Catheterized } \\
\text { state }\end{array}$ & $\begin{array}{c}\text { After Catheter } \\
\text { removal }\end{array}$ & $\begin{array}{c}\text { Catheterized } \\
\text { state }\end{array}$ & $\begin{array}{c}\text { After Catheter } \\
\text { removal }\end{array}$ \\
\hline Mean+SD & $20.21 \pm 2.03$ & $21.91 \pm 2.95$ & $10.37 \pm 1.02$ & $11.26 \pm 1.54$ & $40.02 \pm 6.44$ & $45.63 \pm 9.67$ \\
\hline Median & 20.00 & 21.00 & 10.00 & 11.00 & 38.00 & 44.00 \\
\hline Range & $17-24$ & $17-27$ & $9-12$ & $9-14$ & $31-50$ & $31-63$ \\
\hline t-test & \multicolumn{2}{|c|}{3.11} & \multicolumn{2}{c|}{3.12} & \multicolumn{2}{c|}{3.16} \\
\hline p-value & \multicolumn{2}{|c|}{$0.0026^{*}$} & \multicolumn{2}{c|}{$0.0025^{*}$} & \multicolumn{2}{c|}{$0.022^{*}$} \\
\hline
\end{tabular}

T-test showed that the means of all the scores after the removal of catheter was significantly higher than that of at catheterised state $(\mathrm{p}<0.01)$. Thus the mean of all the scores after the removal of catheter significantly increased (Shown in table 5).

Analysis of total Beck's Depression Inventory (BDI) score:

Table-6: Comparison of total Beck's Depression Inventory (BDI) score of the patients.

\begin{tabular}{|c|c|c|c|c|}
\hline Descriptive Statistics & $\begin{array}{c}\text { Catheterized state } \\
(\mathbf{n = 4 3})\end{array}$ & $\begin{array}{c}\text { After removal of catheter } \\
(\mathbf{n = 4 3})\end{array}$ & $\begin{array}{c}\text { t-test } \\
\left(\mathbf{t}_{\mathbf{8 4}}\right)\end{array}$ & p-value \\
\hline Mean \pm SD & $28.56 \pm 6.17$ & $22.51 \pm 5.41$ & & 0.07 \\
\hline Median & 29.00 & 21.00 & & \\
\hline Range & $15-39$ & $15-35$ & & \\
\hline
\end{tabular}

T-test showed that the mean total BDI score after the removal of catheter was significantly lower than that of at catheterised state. $\left(\mathrm{t}_{84}=4.07 ; \mathrm{p}=0.0013\right)$. Thus the mean total BDI score after the removal of catheter significantly decreased (Shown in table 6).

\section{Discussion}

Wilde $\mathrm{M}$ et al [3] have rightly told that there is a need of more research to find out ways to minimize catheter associated problems in long-term indwelling catheter users. Information from our study may be of help in this direction.

Abiola, O.O.et alin their study based on patient population of south west Nigeria have commented that the long-standing indwelling urinary catheter was associated with poor QoL and it was further worsened in younger patients and QoL was worse in the patients with per-urethral catheters rather than supra-pubic catheter. Rate of complication was pretty high especially in those with per-urethral catheters and continuous bladder drainage. Patients according to their study result had high prevalence of depression and it had a strong correlation with their QoL. The authors concluded that we need to pay attention to the QoL of patients with indwelling urinary catheter for a prolonged period as it is correlated to the severity of depression in those patients [6]. J R Weese et al have said in their publication that there is shortage of literatures regarding QoL of spouses of stricture urethra patients in spite of the fact that there exists a lot of publications regarding quality of life of stricture urethra patients or patients with catheterized (PUC/SPC) state.

They with help of a unique questionnaire containing 12 questions, assessed the QoL of family members of urethral stricture patients and concluded that, the quality of life of family members are negatively impacted by the status of anterior urethral stricture disease. The setbacks comprise of shrunken social interactions, interruption of sleep, emotional stress in addition to messed up sexual intimacy. That's how the QoL of family members are also affected by the QoL of 


\section{Original Research Article}

patients. This is the reason behind our intent for this study [7]. Another study tells about a sort of different story. Rebecca James et al 8 documented that a good number of catheterized Multiple Sclerosis patients had reported negative or positive changes in QoL related to urinary catheterization. Urinary catheterization did not come out to have a universally negative impact on patient QoL [8].

Transurethral resection of prostate (TURP) was linked to note worthy progress in the overall QOL, as well as urinary symptoms, of patients with Benign Prostatic Hyperplasia (BPH) at 3 months post operatively according to Martin JO' Sullivan et al [9]. In this study they relied on the Montgomery and Åsberg Depression Rating Scale, the Mc Gill Pain Questionnaire, and the QOL questionnaire Short Form-36 for assessing QoL of patients. A good number of BPH patients have history of urinary retention leading to PUC insertion. Here lies the importance of this study in the background of our research. Above findings indirectly convey similar observations as of ours.

J.D. Lubahn et al [10] concluded in their study that most of the patients with urethral stricture disease who are on intermittent self-dilation have expressed moderate difficulty and pain, and minimal inconvenience while doing self dilatation, but they had reported poor quality of life. As in our study we are dealing with young male patient with PUC or SPC in situ and as most of those young males had stricture urethra, this study has a great relevance in this context. It has reinforced our findings.

Costa $\mathrm{P}$ et al [11] has acknowledged in their article that Quality of life (QoL) may be severely affected in patients with spinal cord injury (SCI) and resulting urinary difficulties (UD). They had ventured into validation of a questionnaire to measure the QoL of SCI patients with urinary catheter or urinary difficulties. This study indeed supports the need of our study, although in an indirect manner. Schober J.P et al [12] had concluded in their study that there exists a considerable amount of anxiety and depression amongst patients of stricture urethra and following corrective surgeries there is a documented decreased quantum of anxiety and depression. They go over the fact that, a urethral stricture disease specific questionnaire is needed to further illuminate the interplay of urethral stricture disease with anxiety and depression. This study also scaffolds our background and indirectly supports our findings as most of the stricture urethra patients have either per urethral or supra pubic catheter inserted in their urinary bladder.
Lucas ET et al [13] have stated that significant improvements in urinary symptoms and in quality of life occur after urethroplasty and they are correlated with objective measures. They also reinforce and support to establish our findings regarding improvement of QoL after catheter removal in young male catheterised patients.

In our study we compared patients' QoL and depression status in catheterized state and after catheter removal and we got sort of similar findings as we witnessed statistically significant improvement in QoL in all domains measured by WHOQOL BREF and there was statistically significant improvement in depression status also after catheter removal.

\section{Conclusion}

Substantial poor QoL and significant depression status in catheterised state and statistically significant improvement of the QoL as well as Depression status after catheter removalhave been observed. Counselling of such patients regarding QoL and Psychiatry consultation for management of depression may be deemed necessary. It is further recommended that counselling of their spouses or caregivers may be needed as the disease process puts considerable impact on their lives also. Study on QoLof spouses or caregivers of these patients may also be planned to objectively observe the same.

\section{Contribution by different authors}

a) First Author: Research Idea, Data Collection, Literature Search, Statistical Analysis, Writing of Manuscript

b) Second Author: Literature Search, Guidance to First Author in Statistical Analysis and in Writing of Manuscript

c) Third Author (Corresponding Author): Research Idea, Guidance to First Author in Data Collection, Literature Search, Statistical Analysis, Correspondence to Editor for Publication

What does this study add to existing knowledge?: This study has quantified the QoL and Depression status of young male catheterised patients and has documented significant improvement of the same after catheter removal. It also has irked question in our mind regarding the need of study of QoL, Depression and Anxiety status of the spouses or caregivers of these patients which we were able to find very few in present literature. 


\section{Original Research Article}

Funding: Nil, Conflict of interest: None

Permission of IRB: Yes

\section{References}

1. Ikuerowo SO, Ogunade AA, Ogunlowo TO, et al. The burden of prolonged indwelling catheter after acute urinary retention in Ikeja - Lagos, Nigeria. BMC Urol. 2007Sep26;7:16.DOI:10.1186/1471-2490- 7-16

2. Fumincelli L, Mazzo A, Martins JCA, Henriques FMD, Orlandin L. Quality of life of patients using intermittent urinary catheterization. Revista LatinoAmericana de Enfermagem. 2017; 25:e2906. DOI: http: // dx.doi.org/ 10.1590/1518-8345.1816.2906

3. Wilde MH, McDonald MV, Brasch J, et al. Longterm urinary catheter users self-care practices and problems. J Clin Nurs. 2013 Feb;22(3-4):356-67. doi: 10. 1111/jocn.12042.

4. Skevington SM, Lotfy M, O'Connell KA; WHOQOL Group. The World Health Organization's WHOQOLBREF quality of life assessment: psychometric properties and results of the international field trial. A report from the WHOQOL group. doi: 10.1023/B: QURE.0000018486.91360.00

5. Beck AT, Ward $\mathrm{CH}$, Mendelson $\mathrm{M}$, et al. An inventory for measuring depression. Arch Gen Psychiatry. 1961 Jun;4:561-71.

6. Abiola, O.O. \& Ogunwobi, Olorunfemi \& WilliamsAbiola Oyeronke, Titilope \& Ayeni Shola, Christopher \& Adeniyi Segun, Oladele. Quality of life and prevalence of depressive symptoms among patients on prolonged indwelling urinary catheters: A study from South west, Nigeria. International Journal of Medicine and Medical Sciences.2016; 8. 96-104.

7. Weese JR, Raup VT, Eswara JR, Marshall SD, Chang AJ, Vetter J, et al. Anterior urethral structure disease negatively impacts the quality of life of family members. Advances Urology. 2016; 20; 16-20.

8. Rebecca James, Heidi E. Frasure, and Sangeeta T. Mahajan. Urinary Catheterization May Not Adversely Impact Quality of Life in Multiple Sclerosis Patients. ISRN Neurology, vol. 2014, Article ID 167030, 4 pages, 2014. https://doi.org/10. 1155/2014/167030.

9. Martin JO' Sullivan AFRCSI, Colette Murphy (FFARCSI), Conor Deasy MB, Gabrielle Iohom (FFARCSI), Eamon A Kiely (FRCSI), George Shorten (FFARCSI). Effects of transurethral resection of prostate on the quality of life of patients with benign prostatic hyperplasia. Journal of the American College of Surgeons. Volume 198, Issue 3, March 2004, 394403.https://doi.org/10.1016/j. jamcollsurg. 2003. 10.016

10. Lubahn JD, Zhao LC, Scott JF, et al. Poor quality of life in patients with urethral stricture treated with intermittent self-dilation. J Urol. 2014 Jan;191(1):143-7. doi: 10.1016/j.juro.2013.06.054. Epub 2013 Jun 29.

11. Costa P, Perrouin-Verbe B, Colvez A, et al. Quality of life in spinal cord injury patients with urinary difficulties. Development and validation of qualiveen. Eur Urol. 2001 Jan; 39 (1):107-13. DOI:10.1159/ 0000 52421

12. Schober JP, Stensland KD, Breyer BN, et al. Effect of Urethroplasty on Anxiety and Depression. J Urol. 2018 Jun;199(6):1552-1556. doi: 10.1016/j.juro. 2018. 01. 074. Epub 2018 Feb 3.

13. Lucas ET, Koff WJ, Rosito TE, Berger M, Bortolini T, Silva B. Assessment of satisfaction and Quality of Life using self - reported questionnaires after urethroplasty: a prospective analysis. International Brazilian Journal of Urology: official journal of the Brazilian Society of Urology. 2017;43(2):304-310. doi: 10. 1590/S1677-5538.IBJU.2016.0207.

\section{How to cite this article?}

Pramanik S, Paul U.K, Pal D.K. Quality of life of young male catheterized patients. Int J Med Res Rev 2018; 6(07):372377. doi:10.17511/ijmrr.2018.i07.06. 